geographical distribution of the universities with medical schools where the twelve national radium centres had been established, it became obvious that there were considerable areas in England which could not be adequately covered by them. It is likely, in the near future, that regional radium centres will be established to serve these areas, the main policy of concentration at centres adequately staffed and equipped still being preserved.

The chief aim of the Commission for the first five years of its existence is not only to get the best facilities for radium treatment at these recognised centres, but also to be able to assess quantitatively at the end of this time exactly what the value of the radium has been in the treatment of cancer. All the centres keep their clinical records on forms which have been devised and issued by the Commission, and the information from these forms is to be collected yearly and assembled on statistical cards, the general form of which has been agreed upon in consultation with Prof. Major Greenwood. In this way it should be possible year by year to obtain information of the number of people treated, the various sites of cancer which have been treated, all technical details of the treatment, and progress of the patients.

Reference is made in the Report to the work at the Westminster Hospital with what is known as the 'four gramme bomb'. The trial with this appliance was limited in the first instance to cases of malignant disease originating in the breast, stomach, and prostate, and after a period of more than a year the conclusion has been reached that, under present conditions, this form of therapy cannot be recommended for the treatment of cancer in these regions. The Commission takes the view that surface treatment with radium may be better developed by dividing the bomb into smaller units.

Under the terms of its charter, the Commission has two main obligations imposed upon it in administering the national radium; and whilst it has considered that its most pressing duty is to " promote the treatment of the sick throughout Great Britain ", it has also taken steps to forward the "advancement of knowledge of the best methods of rendering such treatment". With this latter object in view, it has allocated $1 \mathrm{gm}$. of radium element to the Medical Research Council and $0 \cdot 18 \mathrm{gm}$. to the National Physical Laboratory. The policy of making such allocations to large corporate bodies in touch with individuals specially qualified to conduct the kinds of research work involved obviously has many advantages. As stated in the present Report, it is an encouraging sign of the activity of experimental research in radium that within a few months of completing the arrangements with the Medical Research Council ninety-five per cent of the loaned radium had been allocated to research groups.

\section{Human Embryology.}

CCASIONALLY children are born with the terminal part of an arm or leg represented by a mere rudiment, or a whole segment may be missing as if an amputation had been performed within the uterus. Dr. George Streeter, director of the Carnegie Laboratory of Embryology, has made an important addition to our knowledge of such abnormalities (Contributions to Embryology, 1930, vol. 22, pp. 3-46). Having numerous examples of such abnormalities at his disposal, he has been able to throw light on many points which have hitherto been obscure.

It has usually been supposed that fibrous bandsknown as amniotic bands-formed round the growing limb of the fotus, causing a constriction, ultimately led to the death and shedding of the distal part of the limb. Dr. Streeter's investigations throw a new light on these encircling bands. They are not formed from the amnion but are developed as fibrous rings from the tissues of the necrosing limb. A survey of the evidence collected and tabulated by Dr. Streeter leaves no doubt in the medical mind that intra-uterine amputations are the result of a partial failure of the placental circulation, which leads to gangrene of the fœetal limbs-just as a partial failure of circulation in the adult may lead to gangrene of the extremities.

Fotal tissues react to lack of blood quite differently from adult tissues. At the zone where separation is to take place between the living and dead parts of the fœetal limb, the lymph thrown out becomes organised and forms the constricting rings of tissue, known as 'amniotic bands'. The unnourished segment of the limb, being bathed in amniotic fluid, undergoes only partial death, parts of it surviving to form an irregularly shaped hand or foot.

Curiously enough, liability to intra-uterine amputation has been shown to be inherited in a few instances.

In the same volume, Dr. R. H. Hunter clears up certain obscurities relating to the development of the human vagina and hymen. In the sixth week of development the vagina is represented by a canal formed out of the fused lower ends of the Mullerian ducts. Thereafter the canal becomes represented by a cord of epithelial cells, this cord, which represents the vagina, continuing to elongate until the end of the fourth month. In the fifth month of development, the solid core of vaginal epithelium begins to proliferate rapidly on all sides, distending the canal round the corner of the uterus at the upper end and pressing against the wall of the vulva (urogenital sinus) at the lower end. The central cells degenerate and the lumen of the vagina is thus formed. The hymen, which represents part of the wall of the urogenital sinus, is formed out of the vagina-vulvar junction by the expansion of the lower end of the vaginal cord. The phylogenetic significance of these vaginal changes is still unexplained.

\section{University and Educational Intelligence.}

Belfast.-Dr. J. S. Young, lecturer in experimental pathology and assistant director of cancer research in the University of Leeds, has been appointed Musgrave professor of pathology.

Cambridar.-Mr. A. G. Brighton (Christ's College) has been appointed curator of the Sedgwick Museum of Geology.

The Council of the Senate recommends that the Goldsmiths' readership in metallurgy be discontinued, and that a Goldsmiths' professorship in metallurgy be established, with a stipend of $£ 1200$ a year. The General Board recommends that a new faculty of geography and geology be instituted in the University. This faculty would include the Departments of Geology, Mineralogy and Petrology, Geography, Geodesy, and Geophysics.

At Emmanuel College, Prof. C. E. Tilley, professor of mineralogy and petrology, has been elected to a professorial fellowship.

V. V. Narlikar (Fitzwilliam House) has been elected to an Isaac Newton studentship, and H. R. Hulme (Gonville and Caius College) has been elected to an additional Isaac Newton studentship.

London.-Dr. F. C. Benham, Sir Ernest Cassel lecturer in commerce at the London School of Economics, has been appointed University reader in 